\title{
In Situ Investigation of the Formation Kinematics of Plasma-Generated Silver Nanoparticles
}

\author{
Daniel Tasche 1,2, Mirco Weber ${ }^{1,3}$, Julia Mrotzek ${ }^{1}$, Christoph Gerhard ${ }^{1}{ }^{\circledR}$, Stephan Wieneke ${ }^{1}$, \\ Wiebke Möbius ${ }^{4}$, Oliver Höfft ${ }^{5}\left(\mathbb{D}\right.$ and Wolfgang Viöl ${ }^{1, *(1)}$ \\ 1 Faculty of Engineering and Health, HAWK University of Applied Sciences and Arts, Von-Ossietzky-Str. \\ 99/100, 37085 Göttingen, Germany; daniel.tasche2@hawk.de (D.T.); mirco.weber@hawk.de (M.W.); \\ julia.mrotzek@hawk.de (J.M.); christoph.gerhard@hawk.de (C.G.); stephan.wieneke@hawk.de (S.W.) \\ 2 Faculty of Natural and Materials Science, Clausthal University of Technology, Robert-Koch-Straße 42, 38678 \\ Clausthal-Zellerfeld, Germany \\ 3 Institute of Inorganic Chemistry, Georg August University of Göttingen, Tammannstraße 4, \\ 37077 Göttingen, Germany \\ 4 Department of Neurogenetics, Max Planck Institute of Experimental Medicine, Electron Microscopy Core \\ Unit, Hermann-Rein-Str. 3, 37075 Göttingen, Germany; moebius@em.mpg.de \\ 5 Institute of Electrochemistry, Clausthal University of Technology, Arnold-Sommerfeld-Straße 6, 37678 \\ Clausthal Zellerfeld, Germany; O.Hoefft@pe.tu-clausthal.de \\ * Correspondence: wolfgang.vioel@hawk.de; Tel.: +49-551-3705-218
}

Received: 20 February 2020; Accepted: 15 March 2020; Published: 19 March 2020

\begin{abstract}
In this publication, it is shown how to synthesize silver nanoparticles from silver cations out of aqueous solutions by the use of an atmospheric pressure plasma source. The use of an atmospheric pressure plasma leads to a very fast reduction of silver ions in extensive solvent volumes. In order to investigate the nanoparticle synthesis process, ultraviolet/visible (UV/VIS) absorption spectra were recorded in situ. By using transmission electron microscopy and by the analysis of UV/VIS spectra, the kinetics of silver nanoparticle formation by plasma influence can be seen in more detail. For example, there are two different sections visible in the synthesis during the plasma exposure process. The first section of the synthesis is characterized by a linear formation of small spherical particles of nearly constant size. The second section is predominated by saturation effects. Here, particle faults are increasingly formed, induced by changes in the particle shape and the fusion of those particles. The plasma exposure time, therefore, determines the shape and size distribution of the nanoparticles.
\end{abstract}

Keywords: silver nanoparticles synthesis; atmospheric pressure plasma; formation kinematic

\section{Introduction}

In recent years, interest in the coupling of plasmas and liquids has strongly increased for scientific and technological reasons. The synthesis of nanoparticles by means of an atmospheric pressure plasma discharge ignited above a solution has attracted attention [1]. In the areas of medicine [2], textile technology [3], printing technology [4], biotechnology [5], and sensor technology, especially surface-enhanced Raman scattering [6], the silver nanoparticle creation is of particular interest due to its versatile application. The strong antibacterial effect of silver nanoparticles is especially useful in the medical field [2].

Silver nanoparticle synthesis is usually achieved by reduction via sodium borohydride [7]. It is also possible to obtain silver nanoparticles by laser ablation of a silver solid within a solution [8], with gamma radiation, via UV-photoreduction [9], or through high-temperature reactions [10]. There is also an ecologically valuable way to synthesize silver nanoparticles of different sizes by using 
microalgae [11], cyanobacteria [12], plant extracts [13], enzymes [14], bacteria [15], and fungi [16]; this is the so-called green silver nanoparticle synthesis.

Microplasmas are often used for the plasma synthesis of nanoparticles under atmospheric pressure in combination with liquids $[17,18]$ or for layer-forming processes [19]. Chemical-reducing agents can be avoided by using a plasma with the effect that the reaction times are fast [18] and the reaction can be stopped at any time by switching off the plasma power source. In addition, plasma offers a new possibility of material synthesis that is not possible with conventional methods [1].

In this publication, we investigate the synthesis of nanoscale silver particles by using a scalable plasma source. The synthesis of those particles from an aqueous silver nitrate solution is monitored in situ via ultraviolet/visible (UV/VIS) absorption spectroscopy. To investigate the kinetics of particle formation in more detail, different stock solutions and treatment times are used.

\section{Materials and Methods}

\subsection{Formation of Silver Colloid}

For the stock solution, dissolved sodium citrate (WHC GmbH, Hilgertshausen, Germany, 0.77 $\mathrm{mg}, 3 \mu \mathrm{mol}, 5 \mathrm{Eq})$ in water $(600 \mu \mathrm{L})$ was initially provided as a stabilizing agent. Afterward, $600 \mu \mathrm{L}$ sodium citrate solution was added to an aqueous solution of silver nitrate (Carl Roth $\mathrm{GmbH}$ and Co. KG, Karlsruhe, Germany, $\geq 99.9 \%$ ) for stock solution 1 (S1): $0.1 \mathrm{mg}, 0.6 \mu \mathrm{mol}, 1 \mathrm{Eq}$; for stock solution 2 (S2): $0.3 \mathrm{mg}$, $1.8 \mu \mathrm{mol}, 3 \mathrm{Eq}$; for stock solution 3 (S3): $0.5 \mathrm{mg}, 3 \mu \mathrm{mol}, 5 \mathrm{Eq}$; for stock solution 4 (S4): 0.7 $\mathrm{mg}, 4.2 \mu \mathrm{mol}, 7 \mathrm{Eq}$. The stock solutions were generated shortly before plasma treatment, and they are stable and transparent for three months without plasma treatment.

\subsection{Plasma Treatment}

The setup to generate and analyze the nanoparticles is illustrated in Figure 1. The used plasma source, which is described in more detail in [20], generates a non-thermal atmospheric pressure plasma based on a dielectric barrier discharge. The high-voltage electrode is made of stainless steel and the ground electrode of copper, which is coated with aluminum oxide $\left(\mathrm{Al}_{2} \mathrm{O}_{3}\right)$. In this setup, the water surface is an active part of the plasma discharge, forming a surface barrier discharge on the liquid phase. The working distance between the solution surface and the plasma source was fixed at $11 \mathrm{~mm}$. As a working gas, argon 5.0 (Linde AG, Pullach, Germany, $\geq 99.999 \%$ ) with a flow rate of $30 \mathrm{~L} / \mathrm{min}$ and, as a high-voltage source, a plasma generator HV-X20 (Tantec, Lunderskov, Denmark) were used. This generator operated with a measured input power of $P \approx 160 \mathrm{~W}$, a frequency of $f \approx 14.5 \mathrm{kHz}$, and a power density of $P_{\text {density }} \approx 4 \mathrm{~W} / \mathrm{cm}^{3}$ in a plasma volume of about $40 \mathrm{~cm}^{3}$ above and around the polymer material UV-cuvette (Brand GmbH and Co. KG, Wertheim, Germany, $230-900 \mathrm{~nm}, d_{\text {cuvette }}=1 \mathrm{~cm}$ ). The plasma source was cylindrical with a diameter of $80 \mathrm{~mm}$, which can be used above a large area for the synthesis of nanoparticles. To illustrate the scalability of the plasma treatment, Figure 2 shows a $60 \mathrm{~s}$ plasma-treated stock solution S2 with a volume of $30 \mathrm{~mL}$ and a surface area of about $250 \mathrm{~cm}^{2}$. The homogeneous effect of the plasma treatment can be recognized. The coloring of the stock solution resulting from the plasma treatment is explained in Section 3.

\subsection{Plasma Diagnostics}

In order to characterize the plasma discharge regarding rotational temperature, vibrational temperature, and electron density, optical emission spectroscopy (OES) was used. These parameters offer an insight into the collisional parameters of the plasma and offer the possibility of classifying the used plasma source. The spectra were obtained using an Échelle-Spectrometer Aryelle-Butterfly 400 (LTB Lasertechnik Berlin GmbH, Berlin, Germany), calibrated to wavelength and relative intensity, with a wavelength resolution of $<80 \mathrm{pm}$. The optical fiber was placed perpendicular to the plasma effluent so that the plasma emission directly above the surface of the analyzed solution was investigated. For further diagnostics, five spectra between 300 and $960 \mathrm{~nm}$, each with an integration time of 100 
ms, were taken at room temperature and ambient air $\left(20^{\circ} \mathrm{C} ; 36 \%\right.$ relative humidity), dark-corrected, and integrated.

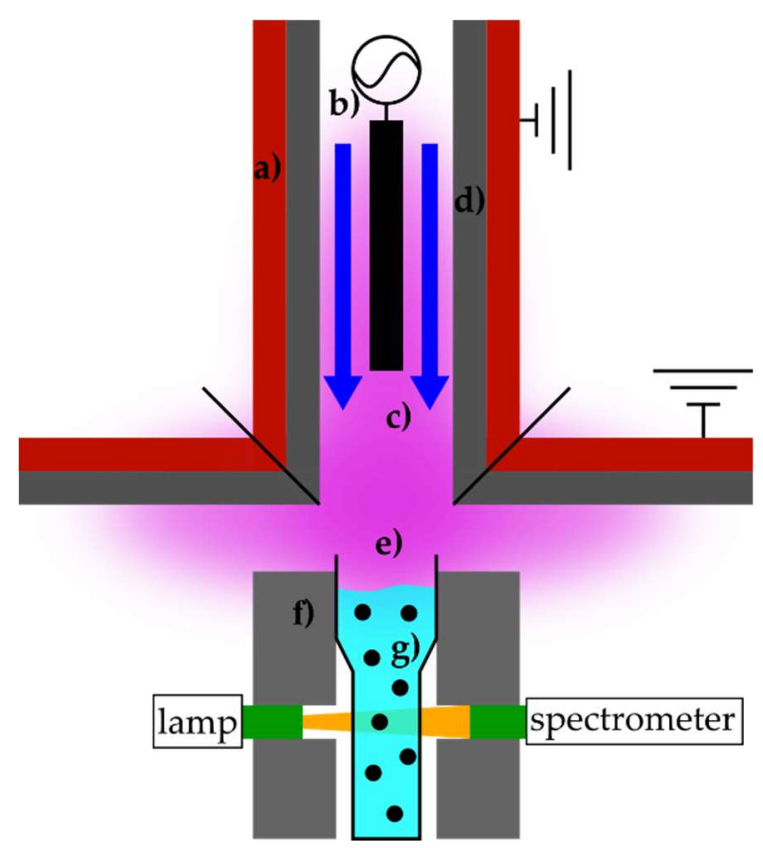

Figure 1. Schematic illustration of silver nanoparticle synthesis using plasma source consisting of (a) ground electrode, (b) high-voltage electrode, (c) working gas flow, (d) dielectric material, (e) plasma discharge, (f) cuvette mount with connections to the spectrometer, and (g) UV cuvette with stock solutions.

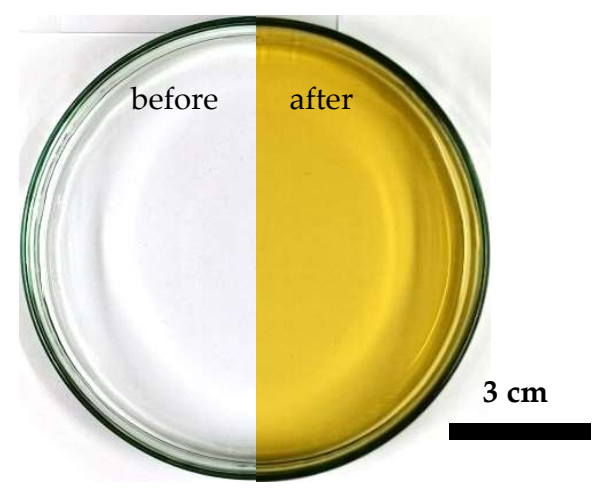

Figure 2. Representation of upscaling feasibility tests with the used plasma source. The untreated stock solution S2 (left) is compared to stock solutions S2 after a plasma treatment time of $60 \mathrm{~s}$ (right) in this illustration. In this upscaling experiment, the treatment area was $250 \mathrm{~cm}^{2}$ and the volume was $30 \mathrm{~mL}$.

The resulting spectrum shows reactive ArI species, $\mathrm{OH}(\mathrm{A}-\mathrm{X}), \mathrm{N}_{2}\left(C^{3} \Pi_{\mathrm{u}}-B^{3} \Pi_{\mathrm{g}}\right), \mathrm{H}_{\alpha}$, and OI, whereas higher excited species are absent. Therefore, $\mathrm{OH}, \mathrm{N}_{2}, \mathrm{H}_{\alpha}$, and $\mathrm{OI}$ most probably originate from the surrounding air and — to a lower extent—-to impurities from the working gas.

To determine the rotational temperature, the Boltzmann-plot method, using Q1 branch lines of the $\mathrm{OH}(\mathrm{A}-\mathrm{X})$ ro-vibrational band, was employed. Necessary parameters were taken from Chidsey et al. [21]. Additionally, the $\mathrm{N}_{2}$-rotational temperature, as well as $\mathrm{N}_{2}$-vibrational temperature, was derived, using the methods described by Peters et al. [22]. The Stark broadening mechanism of $\mathrm{H}_{\alpha}$ was used in order to determine the electron density [23]. The evaluated plasma parameters are summarized in Table 1. 
Table 1. Temperatures and electron density inside the plasma discharge.

\begin{tabular}{cc}
\hline Parameter & Value \\
\hline OH-rotational temperature & $669 \pm 134 \mathrm{~K}$ \\
$\mathrm{~N}_{2}$-rotational temperature & $820 \pm 50 \mathrm{~K}$ \\
$\mathrm{~N}_{2}$-vibrational temperature & $3017 \pm 742 \mathrm{~K}$ \\
Electron density & $3.8 \times 10^{21} \pm 2.4 \times 10^{21} \mathrm{~m}^{-3}$ \\
\hline
\end{tabular}

\subsection{Investigation of Formation Kinetics}

To determine the kinetics of nanoparticle synthesis using an atmospheric pressure plasma, UV/VIS absorption spectra were recorded in situ during the plasma treatment. For those measurements, the UV/VIS spectrometer AvaSpec-UL3648 (Avantes, Apeldoorn, The Netherlands) with a deuterium halogen lamp AvaLight-DH-S (Avantes, Apeldoorn, The Netherlands) was used. The spectra were recorded every $0.5 \mathrm{~s}$ with an integration time of $1.5 \mathrm{~ms}$ and averaged over 50 spectra using the software AvaSoft 8.9 (Avantes, Apeldoorn, The Netherlands). The plasma treatment and, thus, the nanoparticle synthesis took place in a UV cuvette for durations of 5, 10, 20, 30, 60, and $120 \mathrm{~s}$. For the analysis, the spectra were smoothed by a Savitsky-Golay filter and, afterward, evaluated using peak analysis via Origin 2018 (OriginLab Corporation, Northampton, MA, USA).

In order to obtain nanoparticle samples suitable for transmission electron microscopy (TEM), grids (100 mesh hexagonal copper covered with a formvar film) were incubated with droplets of different nanoparticle solutions. Those droplets were dried by carefully absorbing the excess liquid with a piece of filter paper. Then, the nanoparticles were imaged with a LEO912 transmission electron microscope (Carl Zeiss Microscopy, Oberkochen, Germany) by using an on-axis 2k CCD camera (TRS, Moorenweis, Germany). The particle sizes were measured automatically with the software ImageJ 1.52p [24].

Furthermore, the $\mathrm{pH}$-value of the solutions was measured using $\mathrm{pH}$-meter FiveGo F2 with an InLab Flex-Micro electrode (Mettler Toledo, Columbus, OH, USA). In addition, the sample temperature was determined immediately after switching off the plasma with the thermal imaging camera TiS (Fluke Corporation, Everett, WA, USA).

\section{Results and Discussion}

The coloration of the stock solutions after different plasma treatment times is shown in Figure 3. A yellow tint is typical for silver nanoparticles [25] and changes over the plasma treatment time and concentration of the stock solution. For the highly concentrated S4, the coloration shifts to reddish. The optical properties of silver nanoparticles in solution are dependent on particle size [26-28], particle material [25,29], particle shape [30,31], particle coating [32,33], particle stabilization [34], and particle environment $[30,35]$.

(a)

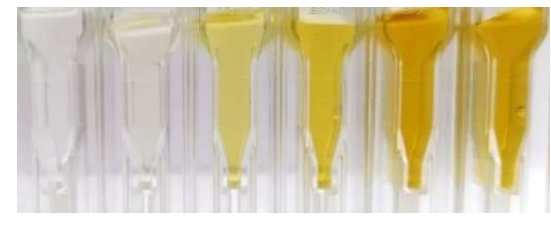

(c)

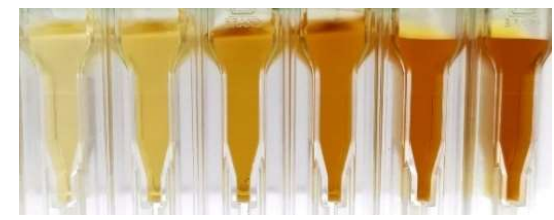

(b)

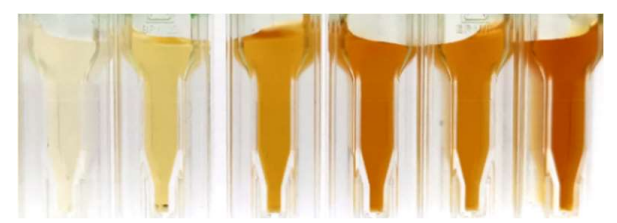

(d)

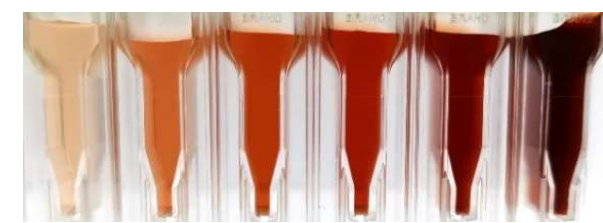

Figure 3. Coloration comparison of the stock solutions (a) S1, (b) S2, (c) S3, and (d) S4 after plasma treatment in UV cuvettes over an ascending plasma treatment time $t$ rising from left to right $(5,10,20$, $30,60,120 \mathrm{~s})$. 


\subsection{Synthesis Pathways}

In order to gain more detailed insights into the formation of silver nanoparticles, some process-determining kinetic parameters and the synthesis routes are explained below. The coloration of the stock solution by the plasma is an indication of the formation of silver nanoparticles [25]. The generated electrons, ions, radicals, and electromagnetic fields provided at the plasma/solution interface lead to the reduction of metal ions dissolved in water and ultimately to the nucleation and formation of nanoparticles $[6,18]$. In the literature, the formation of silver nanoparticles via plasma out of a salt solution is mainly attributed directly to emitted electrons from the plasma discharge [18] and solvated electrons [36,37]:

$$
\mathrm{Ag}^{+}+\mathrm{e}^{-} \rightarrow \mathrm{Ag}^{0}
$$

By contrast, nanoscale gold particles are primarily formed by plasma ion radiation [38] or plasma-induced liquid chemistry [39]. From the investigations presented in this publication, the influence of long-living species and liquid chemistry on the reduction of silver ions is low or not process-determining. This assumption is supported by the fact that there is no significant change in absorbance in the near future after switching off the plasma.

During the whole treatment time, the $\mathrm{pH}$-value stays constant $(6.2 \pm 0.1)$. Kondeti et al. [40] showed that a constant $\mathrm{pH}$-value is a strong indicator for a direct reduction without reacting mainly via intermediates like $\mathrm{H}^{-}, \mathrm{H}^{\bullet}$, or $\mathrm{H}_{2} \mathrm{O}_{2}$. A citrate-based stabilization system was used, which can also create buffer systems, that keep the $\mathrm{pH}$-value in a constant range. These two circumstances made it almost impossible to estimate whether intermediate species formed or not. There is still less knowledge about the concrete reduction pathways. Some research groups claim that the reduction is realized by solvated electrons. In fact, this means that the electrons show strong interactions with the lowest unoccupied molecular orbital (LUMO) of the solvent molecules in the water [36]. Therefore, this reaction pathway is probably responsive for more or less direct reactions between the plasma discharge and the silver ions, whereby the solvent molecules serve as an electron carrier.

Other influences on particle synthesis by (i) UV radiation, (ii) temperature, and (iii) the stabilizer sodium citrate as a reducing agent are discussed beloi) A $3 \mathrm{~mm}$-thick fused silica $\left(\mathrm{SiO}_{2}\right)$ and also a $5 \mathrm{~mm}$-thick window of calcium fluoride $\left(\mathrm{CaF}_{2}\right)$ were positioned above the stock solution. The two glasses differ in their transmission characteristics, which allows the effect of UV radiation on the solution to be observed in defined wavelength ranges. In this modification of the experimental setup, the electrons, ions, and radicals generated in the plasma were excluded and only the UV radiation could interact with the stock solution. While using the $\mathrm{SiO}_{2}$-window, the stock solution remained unchanged. The use of the $\mathrm{CaF}_{2}$-window showed that the $\mathrm{UV}$ radiation in the wavelength range of 130-190 nm emitted from the plasma source is capable of reducing silver ions. When the stock solution was brought into direct contact with the $\mathrm{CaF}_{2}$-window, a silver mirror formed after a plasma treatment time of $t=120 \mathrm{~s}$. If there is a volume of air between the window and the solution, a thin layer of a deep yellow veil formed after $t=120 \mathrm{~s}$, which was not comparable to the result generated by the direct plasma treatment. This circumstance can be explained partly due to the absence of convection mechanisms [40]. It cannot be completely excluded that electrons were formed by the plasma discharge in the air gap between the window and the solution, which could lead to a reduction process of the silver ions. The low formation rate of silver nanoparticles is potentially an indicator for generating a small number of free electrons in the air gap.

(ii) The used plasma source generates a cold, atmospheric non-equilibrium plasma. After a treatment time of $t=120 \mathrm{~s}$, the treated liquid surface heated up by about $5 \mathrm{~K}$. This temperature increase does not explain the fast and controlled silver nanoparticle synthesis.

(iii) The stabilizer sodium citrate is not capable of acting as a reducing agent under the experimental conditions. Therefore, the plasma activation of the pure stabilizer solution and subsequent addition to the silver nitrate solution also did not lead to the formation of silver nanoparticles. 


\subsection{Form and Position of the Plasmon Resonance Peak}

In Figure 4, the progression of the spectral absorbance of the samples S1 and S4 up to a plasma treatment time $t=120 \mathrm{~s}$ is shown. The typical silver nanoparticle plasmon resonance peak above $400 \mathrm{~nm}$ increases with the treatment time $t$. The position of the plasmon resonance peak serves as a benchmark of the nanoparticle size [41]. For the stock solution S1, the maximum wavelength of the plasmon resonance peak is roughly at $412 \mathrm{~nm}$. In S4, the resonance peak is approximately at $423 \mathrm{~nm}$ and, thus, larger nanoparticles were created [41].

A further peak appears around $255 \mathrm{~nm}$, which is a signal of the solution [10]. This peak also increases with the plasma treatment time $t$, which is due to the change in the chemical composition inside the solution. In this wavelength range, nitrites $\mathrm{NO}_{2}{ }^{-}$, nitrates $\mathrm{NO}_{3}{ }^{-}[42,43]$, and hydrogen peroxide $\mathrm{H}_{2} \mathrm{O}_{2}$ [44] can contribute to the signal, which indicates their formation in the stock solution during the plasma treatment.

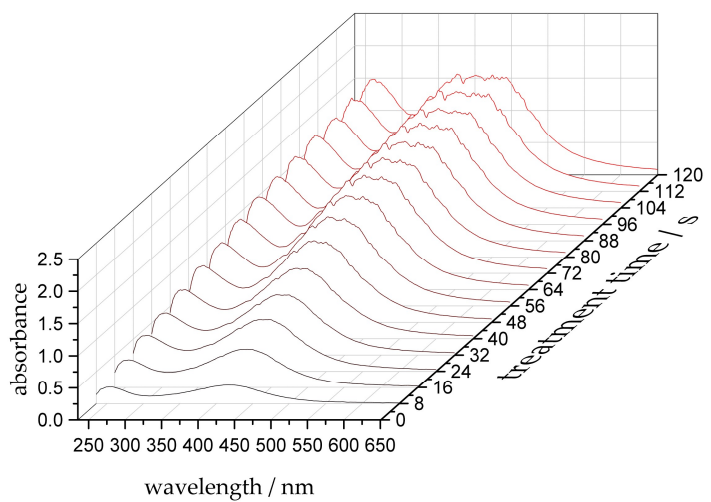

(a)

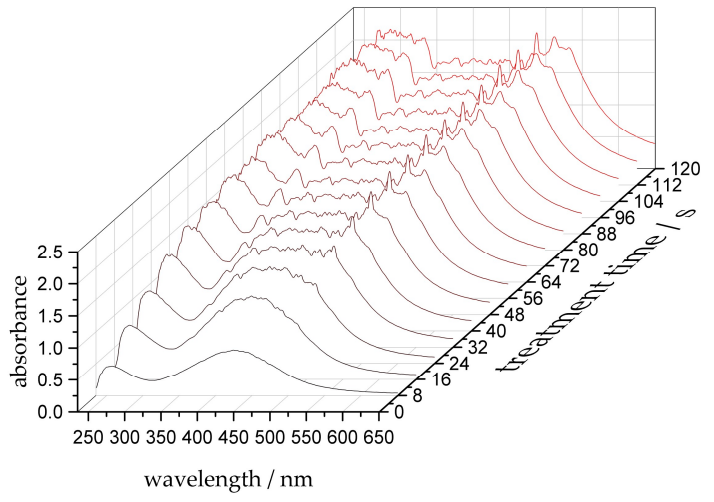

(b)

Figure 4. Absorbance spectra over treatment time $t$, displayed every $8 \mathrm{~s}$ up to a maximum treatment time of $t=120 \mathrm{~s}$ for (a) S1 and (b) S4.

As the plasma treatment time $t$ increases, the plasmon resonance signal becomes broader. A suitable explanation could be a broadening caused by a larger particle size distribution [27], aggregation processes of the created nanoparticles [45], or changes in particle shape [30]. The signal broadening depends on the composition of the stock solution and the ratio between silver and citrate ions, respectively. The stock solution S4 shifts to the reddish wavelength range, mainly attributed to agglomeration processes between the nanoparticles, caused by insufficient stabilization due to the high ratio of silver ions to citrate ions of 7:5 [45,46].

Imaging via transmission electron microscopy (TEM) was used to check the possible aggregation, particle size distribution, and particle shape. TEM images of different stock solutions containing nanoparticles after different treatment times $t$ with corresponding particle size histograms and UV/VIS absorption spectra are illustrated in Figure 5. It is recognizable that at a treatment time of $t=10 \mathrm{~s}$, the particles in stock solution S2 are spherical and the majority of the particles are in the size range of $d_{\text {particle }}$ $\leq 2 \mathrm{~nm}$. In addition, some spherical nanoparticles with particle diameters of $d_{\text {particle }} \leq 10 \mathrm{~nm}$, which possess a higher optical activity [47], are already present. The characteristics of the UV/VIS absorption signal after $t=10 \mathrm{~s}$ are narrow and show a defined shape; these characteristics also symbolize the observed attributes of the formed nanoparticles.

With longer treatment times $t$, the silver nuclei and small nanoparticles grew to larger silver nanoparticles $[48,49]$ in the stock solution S2. At a treatment time of $t=30 \mathrm{~s}$, particle-particle unions, staple faults [50], twinned crystals [48], and also non-spherical nanoparticles appeared. Crystallization processes leading to the resulting crystal structure of silver [48] cause the change in particle shape. After a treatment time of $t=60 \mathrm{~s}$ for stock solution S4, particle-particle unions, non-spherical nanoparticles, and staple faults occur more frequently. Particles with a maximum particle diameter of $d_{\text {particle }} \approx 130$ 
$\mathrm{nm}$ are formed. For large silver nanoparticles, an extinction wavelength around $600 \mathrm{~nm}$ [45] results, which explains the redshift of the spectrum. For the two longer treated stock solutions, the UV/VIS absorption spectra clearly show the diversity of the resulting particles in shape and size.

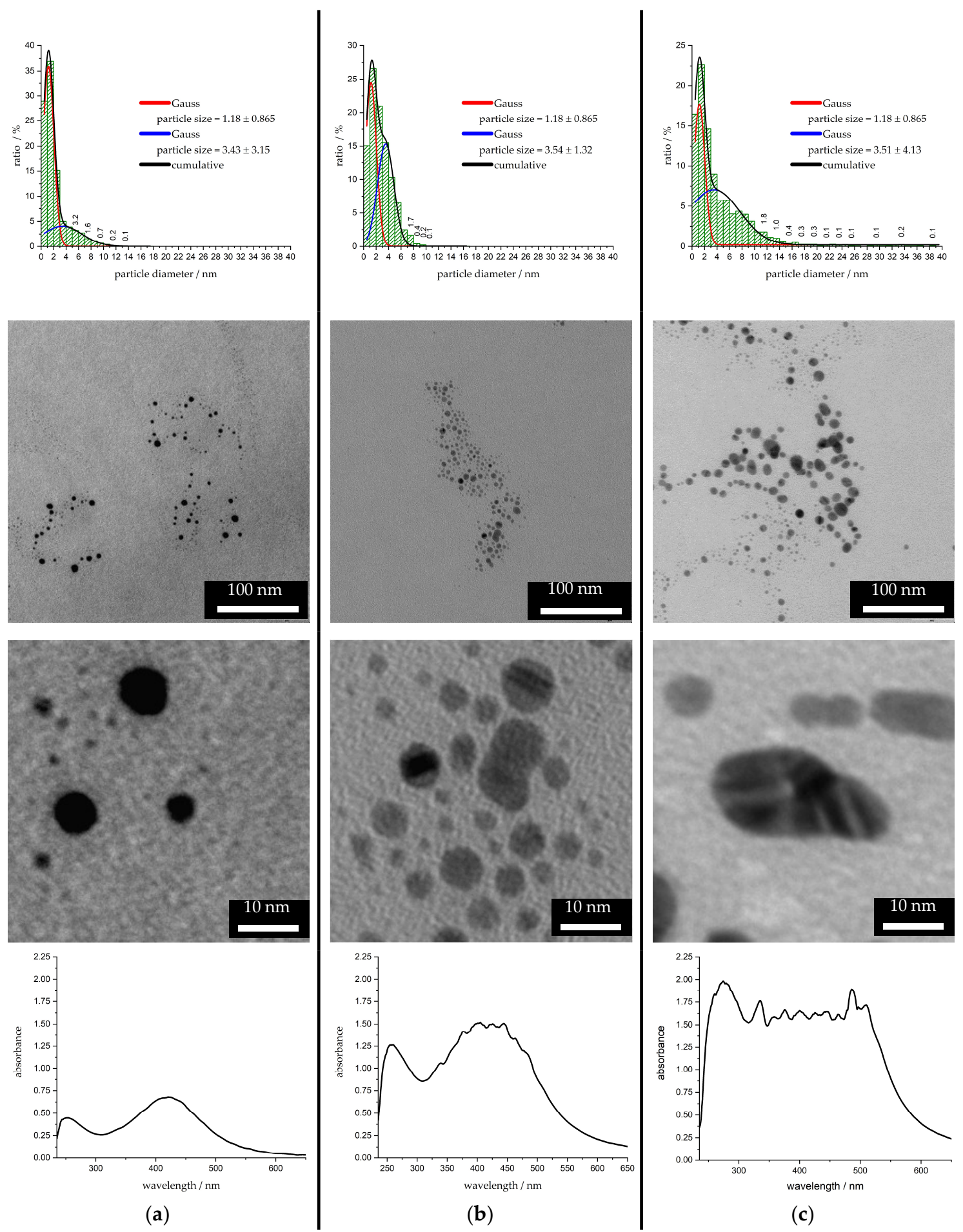

Figure 5. Particle size distribution fitted by Gaussian functions with mean particle size and standard deviation illustrated at the top. UV/VIS absorption spectra and characteristics of the particles are shown at the bottom with TEM-images in between. On the left-hand side: (a) S2 after plasma treatment time of $t=10 \mathrm{~s}$, in the middle: (b) S2 after $t=30 \mathrm{~s}$, and on the right-hand side: (c) S4 after $t=60 \mathrm{~s}$ are shown. 
By fitting the histogram data with two Gauss functions, conclusions are drawn about the synthesis steps nucleation and particle growth. The two Gauss functions symbolize different size regimes. The first Gauss function describes very small nanoparticles or nuclei with a particle diameter $d_{\text {particle }}$ in the range around $2 \mathrm{~nm}$. The position and width of the first Gauss function are determined after a plasma treatment time $t=10 \mathrm{~s}$ and are then kept constant for further analysis. The second Gauss function describes larger particles and agglomerates. The start of nucleation and growth of small nanoparticles is included in the first size regime and, therefore, in the first Gauss function. With the treatment time $t$, the small size regime decreases and the nanoparticles grow. Over the treatment time from $t=10$ to $60 \mathrm{~s}$, the area below the first Gauss function decreased approximately to the half value and the area below the second Gauss function increased to the double value. This means that the occupation of the tiny particle state disappears constantly and the occupation of the state of larger particles and agglomerates grows at the same rate [49]. The small size regime does not empty itself completely as new nuclei continue to be formed by plasma discharge. The plasma also provides strong alternating electric fields and fast electrons, which may lead to the disintegration of large nanoparticles, nuclei, or agglomerates [51]. In addition, it is conceivable that larger particles grow preferentially, whereby smaller particles grow less in size. Unfortunately, no conclusions can be drawn from the experimental data in this context.

\subsection{Absorbance}

The absorbance of silver plasmon resonance peaks increases with the plasma treatment time $t$, as shown in Figure 6 for stock solution S2. The absorbance $A$ is described by the Lambert-Beer law:

$$
A=c \cdot L \cdot \varepsilon\left(d_{\text {particle }}\right)
$$

and depends on the measuring distance $L$, the concentration of nanoparticles $c$, and the absorbance coefficient $\varepsilon\left(d_{\text {particle }}\right)$. The absorbance coefficient $\varepsilon\left(d_{\text {particle }}\right)$ for silver nanoparticles is strongly and not linearly dependent on the particle size $d_{\text {particle }}$ [47]. Over the treatment time $t$, the concentration $c$ of the nanoparticles and the absorbance coefficients $\varepsilon\left(d_{\text {particle }}\right)$ change due to particle growth and nucleation. The absorbance $A$ is measured within the wavelength range of $415-425 \mathrm{~nm}$ depending on the stock solution.

First, the absorbance increases linearly with the treatment time $t$ and then shifts into saturation area. The critical treatment time $t_{c r i t}$ results from the intersection of two linear regressions; on the one hand, from the first $10 \mathrm{~s}$ of treatment (linear growth), and on the other hand, from the last 20 treatment seconds (linear saturation). For the sample S3, this is shown as an example in Figure 6. Up to $t_{c r i t}$, a linear synthesis behavior is assumed within good approximation. The critical treatment times $t_{c r i t}$ for the different stock solutions are summarized in Table 2. In combination with the explanations made in the previous section, the conclusion is drawn that mainly spherical small particles were formed up to $d_{\text {particle }} \leq 10 \mathrm{~nm}$ by the plasma before $t_{\text {crit }}$ was reached. After $t_{\text {crit }}$ has passed, non-linear effects of particle growth such as agglomeration, particle staple faults, or particle shape changes dominate, which broaden the UV/VIS absorption signal rather than change the absorbance. Therefore, the colloids and synthesis become more indefinite and harder to describe in detail. Similar observations and conclusions regarding the phases of nucleation and growth via changes in the UV/VIS absorption spectrum like saturation and linear growth were made by Polte et al. [49] during the chemical synthesis of silver nanoparticles.

Table 2. Critical treatment times $t_{\text {crit }}$ and reaction rate coefficients $k$ for the different stock solutions.

\begin{tabular}{ccccc}
\hline Parameter & S1 & S2 & S3 & S4 \\
\hline$t_{\text {crit }}$ in s & 36.8 & 23.4 & 21.9 & 18.7 \\
$k_{\text {in s }}^{-1}$ & 0.11 & 0.15 & 0.19 & 0.22 \\
\hline
\end{tabular}




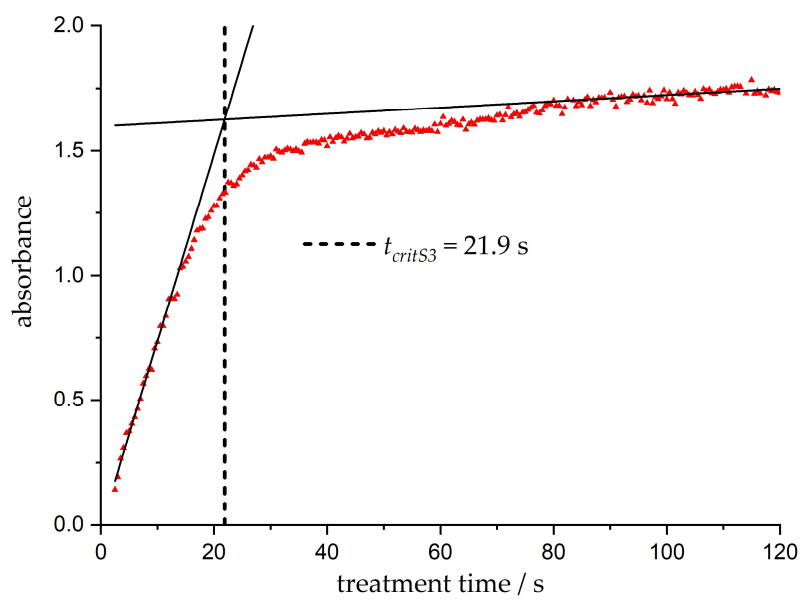

Figure 6. Absorbance over a treatment time of $t=120 \mathrm{~s}$ for stock solution S3 and resulting determination of the critical time $t_{c r i t}$ for plasma treatment.

\subsection{Reaction Rate Coefficient}

A parameter of the reaction kinetics is the reaction rate coefficient $k$ of the silver nanoparticle synthesis, which can be determined by in situ UV/VIS spectrometry. For this purpose, the following simplifications have to be applied. The reduction of silver ions is mainly affected directly by electrons, according to Equation (1). The plasma provides a large amount of electrons for the reduction of silver ions at the interface between liquid and plasma, which is the reason why the reaction corresponds to a pseudo-first order:

$$
\mathrm{Ag}^{+} \rightarrow \mathrm{Ag}^{0}
$$

This allows the reaction to be determined by

$$
c_{t}\left(\mathrm{Ag}^{+}\right)=c_{0}\left(\mathrm{Ag}^{+}\right) \cdot \mathrm{e}^{-\mathrm{kt}},
$$

where $k$ is the reaction rate coefficient, $c_{t}\left(\mathrm{Ag}^{+}\right)$is the silver ion concentration at a treatment time $t$, and $c_{0}\left(\mathrm{Ag}^{+}\right)$is the initial silver ion concentration before treatment. The reaction rate coefficient $k$ can be obtained by [52]

$$
\begin{gathered}
k=-\ln \left(\frac{c_{t}\left(\mathrm{Ag}^{+}\right)}{c_{0}\left(\mathrm{Ag}^{+}\right)}\right) \cdot \frac{1}{t}, \\
k=-\ln \left(\frac{c_{\max }\left(\mathrm{Ag}^{0}\right)-c_{t}\left(\mathrm{Ag}^{0}\right)}{c_{\max }\left(\mathrm{Ag}^{0}\right)}\right) \cdot \frac{1}{t} .
\end{gathered}
$$

Assuming that the silver ion concentration is dependent on and, hence, approximately proportional to the absorbance $A$ of the Lambert-Beer law (Equation (2)), $k$ results in

$$
k=-\ln \left(\frac{A_{\max }-A_{t}}{A_{\max }}\right) \cdot \frac{1}{t},
$$

with $A_{\max }$ for the maximum absorbance and $A_{t}$ as absorbance at a treatment time $t$. However, it should be mentioned that the applied model does not consider all contributing phenomena such as diffusion of silver ions from the liquid volume to its surface. It is, thus, an idealized approach for the description of the process.

The slope of the linear regression taken from the Arrhenius plot in Equation (6) over the plasma treatment time $t$ to $t_{\text {crit }}$ results in the reaction rate coefficient $k$, summarized for the various stock solutions in Table 1 . The reaction rate $k$ in the linear synthesis range increases more strongly if the silver nitrate concentration of the stock solution is very high and vice versa. 


\section{Conclusions}

The reduction of silver ions and the generation of nanoparticles were realized successfully by means of an atmospheric pressure plasma source. It was possible to observe the formation kinetics of silver nanoparticles in situ via UV/VIS-spectroscopy in a detailed temporal resolution. By transmission electron microscopy (TEM), the time-dependent alterations of the nanoparticle shape could be illustrated properly. The shape and number distribution were found to be in good accordance with the absorbance signals from the UV/VIS spectra. With this knowledge, clues arose to estimate the particle formation process in two different main synthesis phases within the considered time range. The analytical method of in situ UV/VIS-spectroscopy can be used to control the atmospheric pressure plasma reduction process in order to gain silver nanoparticles in a specifically defined quality.

For future research, the influence of plasma parameters such as working gas, power input, and working distance on nanoparticle synthesis should be evaluated by in situ UV/VIS spectrometry. In a further step, the plasma-generated nanoparticles could be applied in situ on fiber materials such as non-woven fabrics, especially to make use of the antimicrobial properties of silver nanoparticles in this case. Due to its scalability, the plasma source usage is excellently suitable for possible industrial applications.

Author Contributions: Conceptualization, D.T., M.W. and O.H.; Data curation, D.T.; Funding acquisition, S.W. and W.V.; Investigation, D.T., J.M. and W.M.; Methodology, D.T. and M.W.; Project administration, S.W. and W.V.; Resources, S.W. and W.V.; Supervision, C.G., S.W. and W.V.; Visualization, D.T.; Writing-original draft, D.T.; Writing-review \& editing, M.W., C.G. and O.H. All authors have read and agreed to the published version of the manuscript.

Funding: This research was funded by the Volkswagen Foundation (VWZN3102) and the Federal Ministry of Education and Research of Germany (13FH6I02IA).

Acknowledgments: We deeply thank Darius Rohleder and Peng Wentao from the Georg August University of Göttingen, as well as Roger Skarsten, Martin Bellmann, and Jannik Schulz from the HAWK University of Applied Sciences and Arts for the great support and help.

Conflicts of Interest: The authors declare no conflict of interest.

\section{References}

1. Mariotti, D.; Sankaran, R.M. Perspectives on atmospheric-pressure plasmas for nanofabrication. J. Phys. D: Appl. Phys. 2011, 44, 174023. [CrossRef]

2. Kubik, T.; Bogunia-Kubik, K.; Sugisaka, M. Nanotechnology on duty in medical applications. Curr. Pharm. Biotechnol. 2005, 6, 17-33. [CrossRef] [PubMed]

3. Haji, A.; Qavamnia, S.S.; Barani, H. In situ synthesis of silver nanoparticles onto cotton fibres modified with plasma treatment and acrylic acid grafting. Micro Nano Lett. 2013, 8, 315-318. [CrossRef]

4. Lai, C.Y.; Cheong, C.F.; Mandeep, J.S.; Abdullah, H.B.; Amin, N.; Lai, K.W. Synthesis and characterization of silver nanoparticles and silver inks: Review on the past and recent technology roadmaps. J. Mater. Eng. Perform. 2014, 23, 3541-3550. [CrossRef]

5. Thakkar, K.N.; Mhatre, S.S.; Parikh, R.Y. Biological synthesis of metallic nanoparticles. Nanomedicine 2010, 6, 257-262. [CrossRef] [PubMed]

6. Chang, F.-C.; Richmonds, C.; Sankaran, R.M. Microplasma-assisted growth of colloidal Ag nanoparticles for point-of-use surface-enhanced Raman scattering applications. J. Vac. Sci. Technol. A 2010, 28, L5-L8. [CrossRef]

7. Chou, K.-S.; Ren, C.-Y. Synthesis of nanosized silver particles by chemical reduction method. Mater. Chem. Phys. 2000, 64, 241-246. [CrossRef]

8. Mafuné, F.; Kohno, J.-Y.; Takeda, Y.; Kondow, T.; Sawabe, H. Structure and Stability of Silver Nanoparticles in Aqueous Solution Produced by Laser Ablation. J. Phys. Chem. B 2000, 104, 8333-8337. [CrossRef]

9. Courrol, L.C.; de Oliveira Silva, F.R.; Gomes, L. A simple method to synthesize silver nanoparticles by photo-reduction. Colloids Surf. A 2007, 305, 54-57. [CrossRef]

10. Šileikaitè, A.; Puišo, J.; Prosyčevas, I.; Tamulevičius, S. Investigation of silver nanoparticles formation kinetics during reduction of silver nitrate with sodium citrate. Mater. Sci. 2009, 15, 21-27. 
11. Mahdieh, M.; Zolanvari, A.; Azimee, A.S. Green biosynthesis of silver nanoparticles by Spirulina platensis. Sci. Iran. 2012, 19, 926-929. [CrossRef]

12. Patel, V.; Berthold, D.; Puranik, P.; Gantar, M. Screening of cyanobacteria and microalgae for their ability to synthesize silver nanoparticles with antibacterial activity. Biotechnol. Rep. 2015, 5, 112-119. [CrossRef] [PubMed]

13. Shankar, S.S.; Rai, A.; Ahmad, A.; Sastry, M. Rapid synthesis of Au, Ag, and bimetallic Au core-Ag shell nanoparticles using Neem (Azadirachta indica) leaf broth. J. Colloid Interface Sci. 2004, 275, 496-502. [CrossRef]

14. Schneidewind, H.; Schüler, T.; Strelau, K.K.; Weber, K.; Cialla, D.; Diegel, M.; Mattheis, R.; Berger, A.; Möller, R.; Popp, J. The morphology of silver nanoparticles prepared by enzyme-induced reduction. Beilstein J. Nanotechnol. 2012, 3, 404-414. [CrossRef]

15. Saifuddin, N.; Wong, C.W.; Yasumira, A.A.N. Rapid biosynthesis of silver nanoparticles using culture supernatant of bacteria with microwave irradiation. E-J. Chem. 2009, 6, 61-70. [CrossRef]

16. Vahabi, K.; Mansoori, G.A.; Karimi, S. Biosynthesis of silver nanoparticles by fungus trichoderma reesei (a route for large-scale production of agnps). Insci. J. 2011, 65-79. [CrossRef]

17. Mariotti, D.; Patel, J.; Švrček, V.; Maguire, P. Plasma-liquid interactions at atmospheric pressure for nanomaterials synthesis and surface engineering. Plasma Process. Polym. 2012, 9, 1074-1085. [CrossRef]

18. Richmonds, C.; Sankaran, R.M. Plasma-liquid electrochemistry: Rapid synthesis of colloidal metal nanoparticles by microplasma reduction of aqueous cations. Appl. Phys. Lett. 2008, 93. [CrossRef]

19. Deng, X.; Leys, C.; Vujosevic, D.; Vuksanovic, V.; Cvelbar, U.; Geyter, N. de; Morent, R.; Nikiforov, A. engineering of composite organosilicon thin films with embedded silver nanoparticles via atmospheric pressure plasma process for antibacterial activity. Plasma Process. Polym. 2014, 11, 921-930. [CrossRef]

20. Bellmann, M.; Ochs, C.; Harms, M.; Viöl, W. Plasma Nozzle. Patent: DE102016209097A1, CN108781498A EP3430864A1 WO2017157975A1, 25 May 2016.

21. Chidsey, I.L.; Crosley, D.R. Calculated rotational transition probabilities for the A-X system of OH. J. Quant. Spectrosc. Radiat. Transf. 1980, 23, 187-199. [CrossRef]

22. Peters, F.; Hünnekens, B.; Wieneke, S.; Militz, H.; Ohms, G.; Viöl, W. Comparison of three dielectric barrier discharges regarding their physical characteristics and influence on the adhesion properties on maple, high density fiberboards and wood plastic composite. J. Phys. D: Appl. Phys. 2017, 51, 159501. [CrossRef]

23. Hofmann, S.; van Gessel, A.F.H.; Verreycken, T.; Bruggeman, P. Power dissipation, gas temperatures and electron densities of cold atmospheric pressure helium and argon RF plasma jets. Plasma Sources Sci. Technol. 2011, 20, 065010. [CrossRef]

24. Schneider, C.A.; Rasband, W.S.; Eliceiri, K.W. NIH Image to ImageJ: 25 years of image analysis. Nat. Methods 2012, 9, 671-675. [CrossRef] [PubMed]

25. Scaiano, J.C.; Netto-Ferreira, J.C.; Alarcon, E.; Billone, P.; Alejo, C.J.B.; Crites, C.-O.L.; Decan, M.; Fasciani, C.; González-Béjar, M.; Hallett-Tapley, G.; et al. Tuning plasmon transitions and their applications in organic photochemistry. Pure Appl. Chem. 2011, 83, 913-930. [CrossRef]

26. Evanoff, D.D.; Chumanov, G. Synthesis and optical properties of silver nanoparticles and arrays. Chemphyschem 2005, 6, 1221-1231. [CrossRef]

27. Agnihotri, S.; Mukherji, S.; Mukherji, S. Size-controlled silver nanoparticles synthesized over the range 5-100 $\mathrm{nm}$ using the same protocol and their antibacterial efficacy. RSC Adv. 2014, 4, 3974-3983. [CrossRef]

28. Bastús, N.G.; Merkoçi, F.; Piella, J.; Puntes, V. Synthesis of highly monodisperse citrate-stabilized silver nanoparticles of up to $200 \mathrm{~nm}$ : Kinetic control and catalytic properties. Chem. Mater. 2014, 26, 2836-2846. [CrossRef]

29. Creighton, J.A.; Eadon, D.G. Ultraviolet-visible absorption spectra of the colloidal metallic elements. J. Chem. Soc. Faraday Trans. 1991, 87, 3881-3891. [CrossRef]

30. Noguez, C. Surface Plasmons on metal nanoparticles: The influence of shape and physical environment. J. Phys. Chem. C 2007, 111, 3806-3819. [CrossRef]

31. Zhang, Q.; Ge, J.; Pham, T.; Goebl, J.; Hu, Y.; Lu, Z.; Yin, Y. Reconstruction of silver nanoplates by UV irradiation: Tailored optical properties and enhanced stability. Angew. Chem. Int. Ed. 2009, 48, 3516-3519. [CrossRef]

32. Tzhayik, O.; Sawant, P.; Efrima, S.; Kovalev, E.; Klug, J.T. Xanthate capping of silver, copper, and gold colloids. Langmuir 2002, 18, 3364-3369. [CrossRef] 
33. Ung, T.; Liz-Marzán, L.M.; Mulvaney, P. Controlled method for silica coating of silver colloids. Influence of coating on the rate of chemical reactions. Langmuir 1998, 14, 3740-3748. [CrossRef]

34. Bhat, S.; Maitra, U. Facially amphiphilic thiol capped gold and silver nanoparticles. J. Chem. Sci. 2008, 120, 507-513. [CrossRef]

35. Doty, R.C.; Tshikhudo, T.R.; Brust, M.; Fernig, D.G. Extremely stable water-soluble Ag nanoparticles. Chem. Mater. 2005, 17, 4630-4635. [CrossRef]

36. Siefermann, K.R.; Liu, Y.; Lugovoy, E.; Link, O.; Faubel, M.; Buck, U.; Winter, B.; Abel, B. Binding energies, lifetimes and implications of bulk and interface solvated electrons in water. Nat. Chem. 2010, 2, 274-279. [CrossRef] [PubMed]

37. Burakov, V.S.; Kiris, V.V.; Nedelko, M.I.; Tarasenka, N.N.; Nevar, A.A.; Tarasenko, N.V. Atmospheric pressure plasma in contact with liquid and its application for nanoparticles synthesis. Eur. Phys. J. Appl. Phys. 2017, 79, 10801. [CrossRef]

38. Kaneko, T.; Baba, K.; Harada, T.; Hatakeyama, R. Novel gas-liquid interfacial plasmas for synthesis of metal nanoparticles. Plasma Processes Polym. 2009, 6, 713-718. [CrossRef]

39. Patel, J.; Němcová, L.; Maguire, P.; Graham, W.G.; Mariotti, D. Synthesis of surfactant-free electrostatically stabilized gold nanoparticles by plasma-induced liquid chemistry. Nanotechnology 2013, 24, 245604. [CrossRef]

40. Kondeti, V.S.S.K.; Gangal, U.; Yatom, S.; Bruggeman, P.J. $\mathrm{Ag}^{+}$reduction and silver nanoparticle synthesis at the plasma-liquid interface by an RF driven atmospheric pressure plasma jet: Mechanisms and the effect of surfactant. J. Vac. Sci. Technol. A 2017, 35, 61302. [CrossRef]

41. McKenna, J.; Patel, J.; Mitra, S.; Soin, N.; Švrček, V.; Maguire, P.; Mariotti, D. Synthesis and surface engineering of nanomaterials by atmospheric-pressure microplasmas. Eur. Phys. J. Appl. Phys. 2011, 56, 24020. [CrossRef]

42. Edwards, A.C.; Hooda, P.S.; Cook, Y. Determination of Nitrate in Water Containing Dissolved Organic Carbon by Ultraviolet Spectroscopy. Int. J. Environ. Anal. Chem. 2001, 80, 49-59. [CrossRef]

43. Opländer, C.; Suschek, C.V. The role of photolabile dermal nitric oxide derivates in ultraviolet radiation (UVR)-induced cell death. Int. J. Mol. Sci. 2012, 14, 191-204. [CrossRef] [PubMed]

44. Vaghjiani, G.L.; Ravishankara, A.R. Absorption cross sections of $\mathrm{CH}_{3} \mathrm{OOH}, \mathrm{H}_{2} \mathrm{O}_{2}$, and $\mathrm{D}_{2} \mathrm{O}_{2}$ vapors between 210 and $365 \mathrm{~nm}$ at 297 K. J. Geophys. Res. 1989, 94, 3487. [CrossRef]

45. Quinten, M. The color of finely dispersed nanoparticles. Appl. Phys. B 2001, 73, 317-326. [CrossRef]

46. Patakfalvi, R.; Virnyi, Z.; Dkny, I. Kinetics of silver nanoparticle growth in aqueous polymer solutions. Colloid Polym. Sci. 2004, 283, 299-305. [CrossRef]

47. Paramelle, D.; Sadovoy, A.; Gorelik, S.; Free, P.; Hobley, J.; Fernig, D.G. A rapid method to estimate the concentration of citrate capped silver nanoparticles from UV-visible light spectra. Analyst 2014, 139, 4855-4861. [CrossRef]

48. Chen, M.; Feng, Y.-G.; Wang, X.; Li, T.-C.; Zhang, J.-Y.; Qian, D.-J. Silver nanoparticles capped by oleylamine: Formation, growth, and self-organization. Langmuir 2007, 23, 5296-5304. [CrossRef]

49. Polte, J.; Tuaev, X.; Wuithschick, M.; Fischer, A.; Thuenemann, A.F.; Rademann, K.; Kraehnert, R.; Emmerling, F. Formation mechanism of colloidal silver nanoparticles: Analogies and differences to the growth of gold nanoparticles. ACS Nano 2012, 6, 5791-5802. [CrossRef]

50. Henglein, A.; Giersig, M. Formation of Colloidal Silver Nanoparticles: Capping Action of Citrate. J. Phys. Chem. B 1999, 103, 9533-9539. [CrossRef]

51. Heo, Y.K.; Kim, S.M.; Lee, S.Y. Effects of discharge duration on the size and shape of gold nanoparticles synthesized using solution plasma processing. Phys. Scr. 2010, T139, 014025. [CrossRef]

52. Tran, H.V.; Tran, L.D.; Ba, C.T.; Vu, H.D.; Nguyen, T.N.; Pham, D.G.; Nguyen, P.X. Synthesis, characterization, antibacterial and antiproliferative activities of monodisperse chitosan-based silver nanoparticles. Colloids Surf. A 2010, 360, 32-40. [CrossRef]

(C) 2020 by the authors. Licensee MDPI, Basel, Switzerland. This article is an open access article distributed under the terms and conditions of the Creative Commons Attribution (CC BY) license (http://creativecommons.org/licenses/by/4.0/). 